\title{
Comparative study of topical diltiazem with lateral internal sphincterotomy in management of chronic anal fissure
}

\author{
Gour R ${ }^{1}$, Sharma $\mathbf{J}^{2}$ \\ ${ }^{1}$ Dr. Rajneesh Gour, Assistant Professor, Department of Surgery, Chirayu Medical College and Research Centre, Bhopal, \\ ${ }^{2}$ Dr. Jagdish Sharma, Associate Professor, Upgraded Department of Surgery, SMS Medical College and Hospital, Jaipur.
}

Address for correspondence: Dr. Rajneesh Gour, Email: sunshinejaya @ gmail.com

\begin{abstract}
Introduction: Chronic anal fissure is persistent or recurrent painful linear ulcer situated in anal canal just below the dentate line to the anal verge and fails to heal within 6-8 weeks. For these fissures, partial lateral sphincterotomy is done which diminishes internal anal sphincter hypertonia and anal canal pressure but can lead to long term disturbances of sphincter function. In the present study we have compared medical management by topical diltiazem ointment with established surgical procedure of lateral internal sphincterotomy in the management of chronic anal fissure. Material and Methods: This was a prospective comparative randomised study, carried out on 100 patients of chronic anal fissure at S.M.S. Medical College, Jaipur. Intensity of pain was recorded on 0-10 Numeric Rating Scale and Wong-Baker Faces Pain Rating Scale (Visual analogue scale) on presentation and during follow up visits. Selected patients were put under two groups of 50 participants each, A (study group, diltiazem group) and B (control group, partial lateral sphincterotomy group) using simple randomization technique and were to receive treatment accordingly. Results: $26 \%$ patients of study group and $42 \%$ patients of control group reported no pain at $1^{\text {st }}$ week of treatment. $72 \%$ patients of study group and 94 $\%$ patients of control group reported no pain at $8^{\text {th }}$ week of treatment. Conclusion: Topical diltiazem gel has shown to have several advantages and can be considered first line topical treatment but Partial lateral internal sphincterotomies still gold standard procedure for chronic anal fissure.
\end{abstract}

Key words: Anal Fissures, Topical Diltiazem, Lateral Internal Sphincterotomy, Numeric Rating Scale and wong-baker faces pain rating scale

\section{Introduction}

Fissure (fissure in ano) is a significant health problem and a common anorectal condition. Their prevalence in the general population is probably much higher than that seen in clinical practice, since most patients with symptoms referable to the anorectum do not seek medical attention. Anal fissures affect all age groups but are seen particularly in young and otherwise healthy adults affecting both sexes equally [1]. Anal fissure is a painful linear ulcer situated in anal canal extending from just below the dentate line to the anal verge [2].

The exact etiology of anal fissure is not known, most frequently attributed to trauma to anal canal due to passing of hard stools in constipation, loose watery stools also associated with the development of anal

Manuscript received: $17^{\text {th }}$ Feb 2016

Reviewed: $26^{\text {th }}$ Feb 2016

Author Corrected: 04 $4^{\text {th }}$ March 2016

Accepted for Publication: $13^{\text {th }}$ March 2016 fissure [3]. Low-fibre diets, prior anal surgery is a predisposing factor because scarring from the surgery may cause either stenosis or tethering of the anal canal, which makes it more susceptible to trauma from hard stool [4]. Higher incidence of anteriorly located fissure in women may be attributed to trauma during childbirth. Acute and chronic anal fissures are almost always located in posterior midline with posterior location predominating (women 90\%, men 99\%) [5]. Anterior fissures are much more likely to develop in women due to weak support for the anterior anal canal due to the presence of the vagina anterior to the anus [3].

Other causes of anal fissures are anal intercourse, chron's disease, syphilis, herpes simplex, lymphoma and leukaemia, basal and squamus cell ca, TB, associated systemic diseases like AIDS [6]. 
Pathophysiologic studies suggest increased maximal resting anal pressure (MRAP) leading to anodermal ischemia and development of anal fissure [1]. Anal fissure can be acute or chronic. Majority of anal fissures are acute and relatively short lived, and heals within 1-2 weeks. Whereas chronic anal fissure is persistent or recurrent and fails to heal within 6-8 weeks [7], although a proportion (10-30\%) of chronic anal fissures will eventually resolve with conservative measures, most require further intervention in order to heal [8].

The patient reports severe pain during a bowel movement, with the pain lasting several minutes to hours afterward. The pain recurs with every bowel movement, and the patient commonly becomes afraid or unwilling to have a bowel movement, leading to a cycle of worsening constipation, harder stools, and more anal pain and bleeding which is scant and bright red [3,5]. Significant bleeding usually does not occur with an anal fissure there may be constipation, discharge, pruritus in ano and sentinel tag associated with anal fissure.If gentle inspection does not reveal a fissure, a more vigorous examination following the application of an anesthetic to the anus and anal canal may be necessary.

Treatment of an acute anal fissure is high fiber diet with an adequate water intake with or without stool softeners. Warm sitz baths provide symptomatic relief [9]. Chronic anal fissure will not usually heal without some form of intervention.The management of anal fissure includes medical and surgical measures directed at reduction of internal sphincter and anal canal pressure. Medical management consists of stool softeners, bulking agents, high fibre diet with local anaesthetic ointments and so called chemical sphincterotomywith glyceryltrinitrite ointment, botulinumtoxin, oral nifedipine or diltiazem ointment [1].

Treatment with Botulinum toxin $\mathrm{A}$ is invasive and is associated with complications such as perianal thrombosis, sepsis and pain during injection [10]. Majority of patients using GTN will develop headaches as a side effect of treatment [11]. Calcium channel blocking drugs (e.g., nifedipine or diltiazem) relax the muscles of the internal sphincter. They also dilate the blood vessels of the anoderm and increase the flow of blood[12]. Advanced chronic fissures usually require surgical treatment. Partial lateral internal sphincterotomy is the technique of choice for the treatment of chronic anal fissures [13]. In this procedure, the internal anal sphincter is cut starting at its distal most end at the anal verge and extending into the anal canal for a distance equal to that of the fissure. The cut may extend to the dentate line, but not farther. The cut is made on the left or right side of the anus, hence the name "partial lateral internal sphincterotomy"[3]. Lateral sphincterotomy diminishes internal anal sphincter hypertonia and thereby reduces anal canal pressure. This improves anal mucosal blood flow and promotes the healing of anal fissures. However, sphincterotomy can be associated with long term disturbances of sphincter function [1]. Other surgical methods are ,fissurectomy and v-y advancement flap.In the present study we have compared medical management by topical diltiazem ointment with established surgical procedure of lateral internal sphincterotomy in the management of chronic anal fissure .

\section{Material \& Methods}

This was a prospective comparative randomised study between topical diltiazem and lateral internal sphincterotomy, carried out on 100 patients of chronic anal fissure at S.M.S. Medical College and Hospital, Jaipur from August 2007 to December 2010. Patients presenting in surgery OPD or admitted in Surgery Ward, S.M.S. Hospital, Jaipur (Rajasthan) of age 18 years or more, of both sexes, who presented with anal pain during and after defecation, streaking of blood on stool, constipation and duration of illness more than or equal to 8 weeks with or without additional signs of chronic anal fissure skin tag (sentinel tag), hypertrophied papilla or visible internal anal sphincter muscle fibres at the base of the fissure were included in the study. Patient had acute anal fissure, duration less than 8 weeks, Chronic anal fissure secondary to systemic disease, Past history of any operative treatments for anal fissure were excluded from the study.

A proforma was used to note patients particulars, history, physical examination, per rectal findings, treatment received, post treatment recovery, complications and follow up visit findings.

Intensity of pain will be recorded on 0-10 Numeric Rating Scale and Wong-Baker Faces Pain Rating Scale (Visual analogue scale) ${ }^{27}$ on presentation and during follow up visits.

Routine Blood investigations were done to rule out systemic illness. Selected patients were put under two 
groups A (study group) and B (control group) using simple randomization technique and will receive treatment accordingly.

Group A (Study Group): Consisting of 50 patients who received diltiazem hydrochloride IP $2 \%$ w/w Gel (Diltigesic; Troikaa Pharmaceuticals Ltd.) to be applied anally, 500 to $700 \mathrm{mg} 12$ hourly along with liquid paraffin as stool softener for 8 weeks and daily sitz bath for 7 days. Patient were advised for plenty fluid intake and fibre rich diet.

Group B (Control Group): Consisting of 50 patients were managed by lateral internal sphincterotomy under saddle block anaesthesia. Oral liquids were allowed same day and complete oral intake by next day liquid paraffin as stool softener, daily sitzbath, dry dressing and NSAIDS three times a day for 72 hours were prescribed post operatively. Patients were advised for same plenty fluid intake and fibre rich diet.

Follow up visits were scheduled on $1^{\text {st }}, 3^{\text {rd }}, 5^{\text {th }}$ and $8^{\text {th }}$ week. On each follow up visit progress of patients was noted on proformas regarding pain relief, intensity of pain, discharge and complications.

\section{Results}

100 patients included in the study were of $18-76$ years age range. Mean age was 37.44 years and that of control group was 36 years. $66 \%$ of the patients were male in the study group and $74 \%$ in control group .Pain during or after defecation was primary complaint of all patients included in the study in both study as well as control group. $64 \%$ patients of study group and $56 \%$ patients of control group complained scant bleeding occasionally noted. Chronic constipation was reported in $92 \%$ of study group and $96 \%$ of control group patients and was most common associated symptom along with pain in chronic anal fissure.

Discharge around anal verge was seen in 10 and 16 percent cases of study and control group respectively. Pruritus ani was associated in $22 \%$ cases of study and $12 \%$ cases of control group. Mean duration of symptoms was 11.2 months in study group and 12.1 months in control group. Intensity of pain was recorded on 0-10 Numeric Rating Scale, of the all patients included in the study $6 \%$ were having mild pain ( $1-3$ score ) and $52 \%$ were with moderate ( $4-6$ score ) pain and $42 \%$ reported severe ( $7-10$ score ) pain during or after defecation.Patients followed up at $1^{\text {st }}$ week after treatment, $13(26 \%)$ of the patients in topical diltiazem group reported complete relief of pain while 21 (42\%) of the patients who undergone partial lateral internal sphincterotomy were free of pain at $1^{\text {st }}$ week post operatively. No complete healing of fissure ie epithelisation noted in any group at $1^{\text {st }}$ week. In our study $24(48 \%)$ patients of study group and $38(76 \%)$ patients of control group reported no pain at $3^{\text {rd }}$ week of treatment and complete healing of fissure was noted in $4(8 \%)$ of topical diltiazem group patients and $12(24 \%)$ of sphincterotomy group of patients at $3^{\text {rd }}$ week of follow up .In our study at $5^{\text {th }}$ week of follow up 30 (60\%) patients of topical diltiazem group were completely free of pain and $46(92 \%)$. patients of control group were free of pain.

After 5 week of topical application of diltizem gel healing of fissure was noted in 17 (34\%) of patients while $29(58 \%)$ patients of sphincterotomy group had complete healing of fissure at $5^{\text {th }}$ week. At $8^{\text {th }}$ week, 36 (72\%) of the patients in topical diltigesic group were having complete pain relief with $32(64 \%)$ with complete healing of fissure. In lateral internal sphincterotomy group $47(94 \%)$ patients had complete pain relief with complete healing in $41(82 \%)$ patients.

At $8^{\text {th }}$ week, end point of our study $32(64 \%)$ patients had complete healing of fissure, $15(30 \%)$ patients were either free of pain or at least had reduced intensity of pain and $3(6 \%)$ of patients had no improvement in topical diltizem group. After 8 week of partial lateral internal sphincterotomy $41(82 \%)$ patients had complete healing of fissure, 7 (14\%) had their symptoms relieved. While 2 (4\%) patient had no improvement .In the present study, $72 \%$ of patients were relived with a $2 \%$ topical application of diltiazem at the end of the study period.

\section{Discussion}

Rajabi MA reported complete pain relief in the $75 \%$ patientsof sphincterotomy group and $45 \%$ in the diltiazem group two weeks after the onset of treatment which is similar to our results [14]. Knight Js, Birks M, Farouk R reported in a study after 2-3months of treatment with 2 percent topical diltiazem ointment 75 $\%$ healing of the fissure [15]. In our study Perianal itching was noted in $3(6 \%)$ of the topical diltiazem treated patients, but it was mild severity and all 3 patient could continue the treatment despite this side effect. No other specific side effect noted in study group. In sphincterotomy group $1(2 \%)$ patient had local perianal infection postoperatively which resolved with 
short course of antibiotics and proper hygiene. In this group 1(2\%) patient had developed local hematoma which was resolved in follow up .Hence the need for surgery could be avoided or delayed in these patients. Moreover the topical preparation was well tolerated with only $3 / 50(6 \%)$ patients reporting side effects. All 3 patients had perianal itching which was mild and dissolved during the treatment.Both the surgical sphinctorotomy and the $2 \%$ topical diltiazem gel had a good therapeutic effect on the chronic anal fissure. However, the topical diltiazem gel has shown to have several advantages such as lower complication rates, greater convenience, non-invasiveness, no hospitalization and lower cost.Topical $2 \%$ diltiazem gel used for chronic anal fissure offerssignificant healing rates without significant side-effects, which aidcompliance to the treatment.With complete pain relief in $94 \%$ and healing in $84 \%$ of patients 8 weeks following treatment Partial lateral internal sphincterotomy is still gold standard procedure for chronic anal fissure. However in light of the current findings a topical 2 per cent Diltiazem gel can be considered first line topical treatment for chronic anal fissures.Our findings are in corroboration with earlier workers.

\section{Conclusion}

Both the surgical sphinctorotomy and the $2 \%$ topical diltiazem gel had a good therapeutic effect on the chronic anal fissure. However, the topical diltiazem gel has shown to have several advantages such as lower complication rates, greater convenience, noninvasiveness, no hospitalization and lower cost.In light of the current findings a topical 2 per cent Diltiazem gel can be considered first line topical treatment for chronic anal fissures and Partial lateral internal sphincterotomy still gold standard procedure for chronic anal fissure and should be reserved for patients who do not respond to topical therapy or having recurrence after pharmacologic treatment.

\section{Funding: Nil}

Conflict of interest: None.

Permission of IRB: Yes

\section{References}

1. Marvin L. Corman: Colon and Rectal Surgery, $5^{\text {th }}$ ed. (2005), Lippincott Williams and Wilkins, PP. 255-275.

2. Keith A. Kelly, Michael G. Sarr, Ronald A. Hinder: Mayo Clinic Gastrointestinal Surgery; Saunders (2004)
PP. 599-604.

3. http://www.medicinenet.com/anal_fissure/article.htm

4. Charles J. Yeo: Shackelford's Surgery of Alimentary tract; Sounders, $6^{\text {th }}$ ed. 2007, PP. 2038-2042.

5.AnalFissure.www.emedicine.com/med/topic3532.htm .june2006.

6. Michael M. Henry, Jeremy N. Thompson: Clinical Surgery: Saunders $2^{\text {nd }}$ ed. 2005, PP. 413-417, 422.

7.Ayantunde AA, Debrah

SA.

Current concepts in anal fissures.

World J

Surg. 2006 Dec;30(12):2246-60.

8. Marian Jones Jolm H. Scholefield. Anal fissure and chemical sphincterotomy. Resent Advances In Surgery 2001: 24 .

9. Jensen SL. Treatment of first episodes of acute anal fissure : prospective randomised study of lignocain ointment versushydrocortisone ointment or warm sitz b aths plus bran. Br Med J (Clin Res Ed). 1986 May 3;292(6529):1167-9.

10. Leong AP. Pharmacological treatment of anal fissure--a future role in primary care. Singapore Med J. 2003 Mar;44(3):136-7.

11. Shrivastava UK, Jain BK, Kumar P, Saifee Y. A comparison of the effects of diltiazem and glyceryl trinitrate ointment in the treatment of chronic anal fissure: a randomized clinical trial. Surg Today. 2007;37(6):482-5. Epub 2007 May 28.

12. Bhardwaj R, Vaizey CJ, Boulos PB, Hoyle CH. Neuromyogenic properties of the internal anal sphincter: therapeutic rationale for anal fissures. Gut. 2000 Jun;46(6):861-8.

13. Orsay C, Rakinic J, Perry WB, Hyman N, Buie D, Cataldo P, Newstead G, Dunn G, Rafferty J, Ellis CN, Shellito P, Gregorcyk S, Ternent C, Kilkenny J 3rd, Tjandra J, Ko C, Whiteford M, Nelson R; Standards Practice Task Force; American Society of Colon and Rectal Surgeons. Practice parameters for the management of anal fissures (revised). Dis Colon Rectum. 2004 Dec;47(12):2003-7.

14. Rajabi MA; Comparison between the therapeutic effects of internal sphincterotomy and topical 
diltiazem in anal fissure; Journal of rafsanjan university of medical sciences and health services summer 2007; 6(2 (23)):143-149.
15. Knight JS, Birks M, Farouk R. Topical diltiazem ointment in the treatment of chronic anal fissure. Br J Surg. 2001 Apr;88(4):553-6.

\section{How to cite this article?}

Gour R , Sharma J. Comparative study of topical diltiazem with lateral internal sphincterotomy in management of chronic anal fissure. Int J Med Res Rev 2016;4(3):319-323. doi: 10.17511/ijmrr.2016.i03.06. 